routine childhood immunisations at 2 months and neither BCG nor the beginning of the childhood course is postponed.

Information is not available on the age up to which it is safe to give BCG immunisation without a prior tuberculin test. The Joint Committee on Vaccination and Immunisation has agreed, however, that in the absence of any suggestion of recent contact with tuberculosis a cut off point at 3 months would be sensible. ${ }^{1+}$ The committee also advised that vaccination by the percutaneous multiple puncture technique, using 18-20 needles, is an acceptable alternative to the intradermal technique in infants and neonates. An instrument with an 18 needle magnetic disposable head is now available and convenient to use.

Tuberculin testing of neonates is less common than testing of schoolchildren, but it is surprising that in five districts no action was recommended for grade 2 results in this age group. Indeed in neonates even a grade 1 result should be considered with suspicion, especially if there is any recent history of contact with tuberculosis.

Whoever takes the leading role in devising a district's policy for BCG immunisation, it is appropriate that the consultant in communicable disease control (or other public health physician, if a consultant is not in post) as well as the district immunisation coordinator consult with a chest physician (or physician with an interest in respiratory medicine) about the policy for the schools programme and with a paediatrician on the policy for the programme in neonates. In addition, it would seem prudent to have such policies reviewed by either a district control of infection committee or an immunisation committee.

We thank Mrs M Bezzant for her administrative support, Ms F Majid for her statistical advice, and Drs K Citron,
J Leese, and C Skinner for their helpful comments on this manuscript. We are also grateful to all the immunisation coordinators, consultants in communicable disease control, and others who provided the information for this national survey. 1 Office of Population Censuses and Survevs. Communicable disease statistics.
London: HMSO, 1974-89. (Series MB2.)

2 Registrar General. Annual report. London: HMSO, 1927-73.

3 Sutherland I, Springett VH. The effects of the scheme for BCG vaccination of schoolchildren in England and Wales and the consequences of discontinuing the scheme at various dates. I Epidemiol Community Health 1989;43:15-24

4 Springett VH, Sutherland I. BCG vaccination of schoolchildren in England and Wales. Thorax 1990;45:83-8.

5 Miller C, Morris J, Pollock TM. PHLS inquiry into current BCG vaccination policy. BMF 1984;288:564.

6 Medical Research Council Tuberculosis and Chest Diseases Unit. National survey of notifications of tuberculosis in England and Wales in 1983. BMF 1985;291:658-61.

7 Department of Health. The school BCG vaccination programme. London: Department of Health and Social Security, 1985. (DA(85)27.)

8 Watson JM, Fern KJ, Porter JDH, Whitmore SE. Notifications of tuberculosis in England and Wales, 1982-89. Communicable Disease Report 1991;1:R13-6.

9 Citron KM. BCG vaccination in children. BMf 1990;301:1275

10 Department of Health. BCG immunisation programme: vaccine supply. London: Department of Health, 1989. (Executive Letter (89)93.)

11 Department of Health. BCG immunisation programme: vaccine supply. London: Department of Health 1990. (Executive Letter (90)P/61.

12 Dean AD, Dean JA, Burton JH, Dicker RC. Epi Info, version 5: a word processing, database and statistics program for epidemiology on microcomputers. Atlanta, Georgia: Centers for Disease Control, 1990.

13 Frankenberg RA, Mayon-White RT. The effect of a policy of non-vaccination of schoolchildren on the incidence of tuberculosis in Oxfordshire. of schoolchildren on the incidence

14 Department of Health, Welsh Office, and Scottish Home and Health Department. Immunisation against infectious disease. London: HMSO (in
Depalth press).

15 Rodrigues LC, Gill ON, Smith PG. BCG vaccination in the first year of life protects children of Indian subcontinent ethnic origin against tuberculosis in England. I Epidemiol Community Health 1991;45:78-80.

16 Packe GE, Innes JA. Protective effect of BCG vaccination in infant Asians: a case-control study. Arch Dis Child 1988;63:277-81.

17 Curtis HM, Leck I, Bamford FN. Incidence of childhood tuberculosis after neonatal BCG vaccination. Lancet 1984:i: 145-8.

18 Cundall DB, Pearson SB. Inner city tuberculosis and immunisation policy. Arch Dis Child 1988;63:964-6.

(Accepted 19 June 1992)

\section{Centre National de}

Transfusion Sanguine, Abidjan, Côte d'Ivoire Dominic Savarit, senior medical technologist Richard Schutz, medical officer

Seydou Konate, medical officer

Alain Bondurand, director

National Center for Infectious Diseases, Centers for Disease Control, Atlanta, Georgia, USA

Kevin M De Cock, international activity, division of HIVIAIDS

Eve Lackritz, malaria branch, division of parasitic diseases

Correspondence to: Dr K M De Cock, Projet RETRO-CI, 01 BP 1712, Abidjan, Côte d'Ivoire, West Africa.

BMJ 1992;305:498-501

\title{
Risk of HIV infection from transfusion with blood negative for HIV antibody in a west African city
}

\author{
Dominic Savarit, Kevin M De Cock, Richard Schutz, Seydou Konate, Eve Lackritz, \\ Alain Bondurand
}

\section{Abstract}

Objective-To estimate the risk of infection with HIV (HIV 1 or HIV 2, or both) from transfusion of a screened unit of blood in a high prevalence area in west Africa.

Design-Retrospective cohort study for JanuaryJuly 1991.

Setting-National Blood Transfusion Centre, Abidjan, Côte d'Ivoire.

Subjects - Repeat donors (5831 units of blood) and first time donors (5076 units) in the first five months of 1991 .

Main outcome measures-Prevalence and estimated incidence of HIV infection in repeat and first time donors; estimated rate of potentially infected, HIV antibody negative units; and rate of (false negative) potentially infected units assuming a laboratory test sensitivity of $\mathbf{9 9 \%}$.

Results-Overall HIV prevalence was $11.0 \%$ in first time donors and $2 \cdot 1 \%$ in repeat donors. In the first seven months of 1991, $29 \mathrm{HIV}$ antibody positive (27 HIV 1, 1 HIV 2, 1 dually reactive) donors with a seronegative unit of blood earlier in the year were identified; 26 had donated blood eight weeks or less before their estimated dates of seroconversion and may have been infectious (minimum rate 26/5831
(4.5/1000 potentially infected units)). Estimated incidence of infection in repeat donors was $1 \cdot 2-2 \cdot 5 \%$. Laboratory test insensitivity would result in an estimated 1.1/1000 false negative units from first time donors and $0 \cdot 2 / 1000$ units from regular donors. The overall rate of potentially infected units (all donors, seroconversions, and errors) was estimated at 5.4-10.6/1000.

Conclusions-The risk of HIV infection from a single unit of blood remains substantial $(5 \cdot 4-10 \cdot 6 /$ 1000 units). To prevent infection from blood transfusion in areas of high incidence and prevalence of HIV all but absolutely essential transfusions should be avoided, and donors with low incidence of HIV infection should be selected.

\section{Introduction}

Measures introduced in the industrialised world to prevent transmission of HIV infection by blood transfusions include adherence to more stringent criteria for the use of blood, use of only voluntarily donated blood, exclusion of high risk donors, and universal testing of donated blood for HIV antibodies.' Despite these measures it is estimated that 1 in every $40000-153000$ units of blood transfused in the United States may be 
infected with HIV $\cdot{ }^{1-4}$ A recent study with the diagnostic techniques of virus culture and the polymerase chain reaction found one unit of infected blood in 61171 units of blood collected in the San Francisco area that was negative for HIV antibody. ${ }^{4}$ Currently, about 17 persons are estimated to be infected annually from blood transfusions in France.

Infected units of blood escape detection because of test insensitivity or laboratory error or because the donor is in the period of infection before seroconversion ("window period"). ${ }^{6}$ In the United States seroconverting donors associated with transmission of HIV to transfusion recipients had periods of two to six months between their seronegative and seropositive donations. ${ }^{2}$ In France transmission of HIV was recorded in a quarter of recipients of blood from donors who seroconverted within 12 months after a seronegative donation.?

Rates of HIV infection are high in many countries of sub-Saharan Africa ${ }^{8}$ Although great efforts have been made to introduce HIV antibody screening of blood for transfusion, in many sub-Saharan African countries this intervention has been little evaluated. In this study we attempted to assess the risk of transmission of HIV infection through blood transfusion in Abidjan, Côte d'Ivoire. Understanding of the magnitude of the problem is necessary to suggest ways of reducing further the risk of transmission by this route.

Abidjan, the largest city in Côte d'Ivoire, has a population of about two million. The Centre National de Transfusion Sanguine is responsible for providing a safe supply of blood for the city and the surrounding region. Blood is collected from repeat donors who give blood regularly at the centre or from once only or first time donors at the centre or in the community. Donors at the centre receive refreshments and compensation for transport (\$1.67). Donated blood is screened for HIV 1 and HIV 2 antibodies, syphilis, and hepatitis B surface antigen.

Testing of donated blood for HIV antibodies was introduced in 1987. Since 1990 the centre has received increased international help from the European Community. Since the end of 1990 HIV positive donors have been counselled and requested not to donate blood again. By exclusion of known seropositive donors who could be contacted, the overall (HIV 1 and HIV 2 infected donors combined) seroprevalence in blood from repeat donors has fallen considerably. HIV antibody positive units of blood from repeat donors now represent incident infections since the previous screened donation, or seroprevalent infections in donors not able to be reached for counselling since the previous HIV antibody positive donation.

\section{Materials and methods} HIV SEROLOGY

Donated blood was screened with HIV 1 and HIV 2 whole virus enzyme linked immunosorbent assay

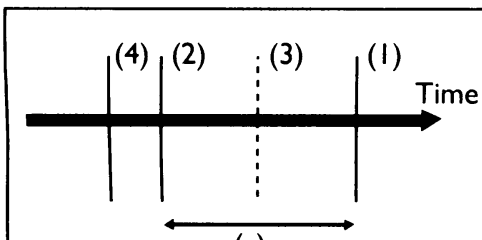

(a)

(b)
(1) Seropositive blood donation

(2) Seronegative blood donation

(3) Midpoint between seropositive and seronegative blood donations (presumed date of seroconversion)

(4) HIV infection (a) Period between last seronegative and first seropositive blood donation (b) Seroconversion period (56 days)

FIG $1-H I V$ infection and seroconversion in repeat blood donors
(ELISA) from one of several manufacturers (Behring, Mannheim, Germany; Diagnostics Pasteur, Paris, France; Abbott Laboratories, Frankfurt, Germany). Positive samples were further tested by ELISA from one of the other sources, and repeatedly reactive specimens were then tested by an assay detecting antibodies to the transmembrane glycoproteins of HIV 1 and HIV 2 (Peptilav 1-2, Diagnostics Pasteur, Paris), ${ }^{9}$ when the reagents were available. All blood which was reactive on the first screening test was discarded.

\section{IDENTIFICATION OF REPEAT BLOOD DONORS WHO} SEROCONVERTED

All HIV antibody positive specimens from repeat donors in the first seven months of 1991 were identified, and records for this period were searched by hand to see whether any of these seropositive units came from donors who had donated earlier in the year. When such donors were identified the time periods between the earlier seronegative and the subsequent seropositive donations were assessed. Seroconversion was assumed to have occurred midway between the dates of the discordant serological results for each donor, as commonly assumed in cohort studies of the natural history of HIV infection. ${ }^{10} 11$ Figure 1 shows this graphically.

If the interval between the dates of the seronegative specimen and the presumed date of seroconversion was eight weeks or less the earlier unit was considered potentially infectious for HIV. ${ }^{26} \mathrm{~A}$ rate of potentially infectious units per total units collected in the first five months of the year was calculated. Because seroconversions would only have been recorded if donors had been tested at least twice this measured rate represents a minimum estimate of potentially HIV infected units.

ESTIMATION OF INCIDENCE OF HIV INFECTION IN REPEAT AND FIRST TIME BLOOD DONORS

From the recorded seroconversions in repeat donors we generated estimates of incidence of HIV infection. Data on the number of repeat donors were not available, only on the number of units from repeat donors. For this reason a range of incidence rates was calculated, based on the likely frequency of donation by repeat donors.

As the prevalence of HIV antibody was similar in repeat and first time donors before exclusion of known positives from the repeat donor population (unpublished data) the incidence of HIV infection in the two groups should be similar. The calculated incidence rates of HIV antibody in repeat donors were applied to the first time donor population, and rates of potentially infected blood units were calculated for both groups as previously described. ${ }^{2}$

For the calculation of incidence of HIV infection it was assumed that each regular donor gave blood every three months (Centre National de Transfusion Sanguine, unpublished data); that detectable antibody developed within eight weeks of HIV infection; that the probability of a regular donor becoming infected with HIV was equal throughout the year; and that blood donations were equally distributed over the year. Figure 2 shows the donation of blood by regular donors. For seroconversion to be detected a donor must be tested at least twice. Donation of blood every three months results in each donor being tested four times during the year and having three separate intervals of three months each, during which seroconversion could be detected. The equal distribution of blood donations over the year means the population of regular donors could be considered as three separate cohorts, each giving blood every three months. For the three cohorts, therefore, there would be a total of nine periods during which HIV infection could be detected. 


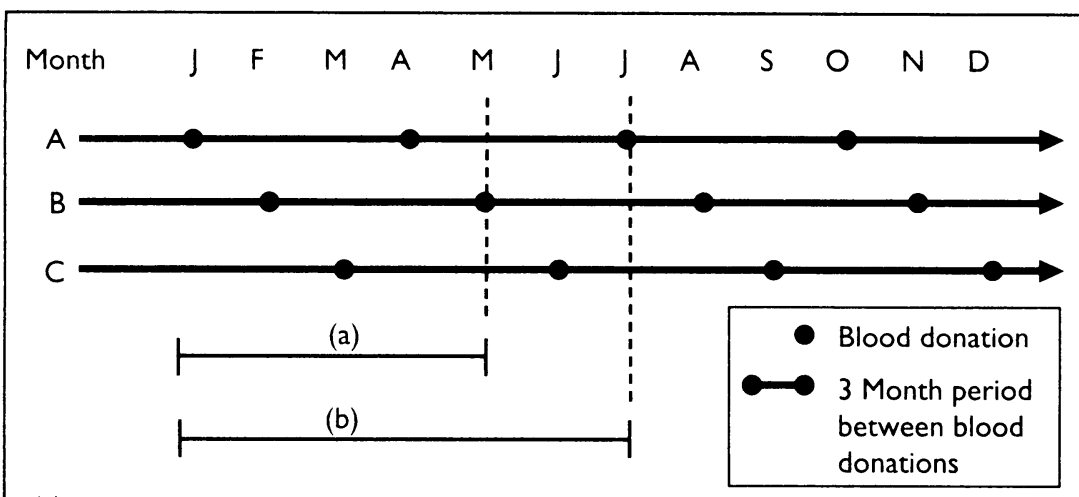

(a) January - May; period studied for incident infection

(b) January - July; period studied for discordant HIV serological test results in repeat donors

FIG 2-Blood donation by repeat donors. $A, B$, and $C$ represent the three cohorts donating four times in the year, assuming blood donations were distributed equally over the year annual incidence.
Incidence rates generated in this way are for a time period of nine months and need to be adjusted for

We looked for seroconversions in regular donors giving blood between January and July inclusive, which encompasses $4 / 9$ periods during which seroconversion could be detected throughout the year.

\section{DETERMINATION OF FALSE NEGATIVE RESULTS}

To calculate a range of number of units of blood incorrectly considered to be negative for HIV antibody, test sensitivity levels of $99 \%, 99 \cdot 5 \%$, and $99.9 \%$ were applied to the observed levels of seroprevalence in units from first time donors and repeat donors.

\section{Results \\ HIV SEROPREVALENCE IN FIRST TIME AND REPEAT DONORS}

Between 1 January and 31 May 1991 a total of 10907 units of blood were collected, $5831(53 \cdot 5 \%)$ units from repeat donors and $5076(46.5 \%)$ from first time donors. The overall prevalence of repeatedly reactive ELISA results was $2 \cdot 1 \%$ in units from repeat donors and

TABLE I-Prevalence of HIV 1 and HIV 2 antibodies in blood donated by repeat and first time donors in Abidjan, Fanuary-April 1991

\begin{tabular}{lcccccc}
\hline & & & \multicolumn{3}{c}{$\begin{array}{c}\text { Distribution of types of HIV reactivity by synthetic } \\
\text { peptide testing of positive units of blood }\end{array}$} \\
\cline { 4 - 7 } & $\begin{array}{c}\text { No of units of } \\
\text { blood tested }\end{array}$ & $\begin{array}{c}\text { No (\%) } \\
\text { positive } \\
\text { by ELISA }\end{array}$ & HIV 1 (\%) & HIV 2 (\%) & $\begin{array}{c}\text { HIV 1 and } \\
\text { HIV.2 2(\%) }\end{array}$ & $\begin{array}{c}\text { No } \\
\text { tested }\end{array}$ \\
\hline Repeat donors & 5831 & $124(2 \cdot 1)$ & 78 & 12 & 10 & 101 \\
First time donors & 5076 & $557(11 \cdot 0)$ & 72 & 15 & 13 & 375 \\
\hline
\end{tabular}

TABLE II - HIV serconversions in repeat blood donors in Abidjan, Fanuary-May' 1991

\begin{tabular}{|c|c|c|c|c|c|c|}
\hline \multirow[b]{2}{*}{ Month } & \multicolumn{4}{|c|}{$\begin{array}{l}\text { No of seronegative units of blood from donors with } \\
\text { subsequently recorded seroconversion }\end{array}$} & \multirow{2}{*}{$\begin{array}{l}\text { No of seronegative units of } \\
\text { blood from donors with } \\
\text { presumed seroconversion } \\
\text { within eight weeks }\end{array}$} & \multirow{2}{*}{$\begin{array}{l}\text { Total No o } \\
\text { units } \\
\text { collected }\end{array}$} \\
\hline & HIV 1 & HIV 2 & $\begin{array}{l}\text { HIV } 1 \text { and } \\
\text { HIV } 2\end{array}$ & Total & & \\
\hline January & 11 & & 1 & 12 & 10 & 1261 \\
\hline February & 5 & & & 5 & 4 & 1028 \\
\hline March & 1 & & & 1 & 1 & 1192 \\
\hline April & 6 & 1 & & 7 & 7 & 1137 \\
\hline May & 4 & & & 4 & 4 & 1213 \\
\hline Total & 27 & 1 & 1 & 29 & 26 & 5831 \\
\hline
\end{tabular}

TABLE III -Numbers of false negative units of blood from repeat and first time blood donors in Abidjan at different test sensitivities, Fanuary-May 1991

\begin{tabular}{|c|c|c|c|c|c|}
\hline & \multirow[b]{2}{*}{ No of units } & \multirow{2}{*}{$\begin{array}{l}\text { Observed } \\
\text { prevalence }\end{array}$} & \multicolumn{3}{|c|}{ Test sensitivity } \\
\hline & & & $99 \%$ & $99 \cdot 5 \%$ & $99.9 \%$ \\
\hline Repea & 5831 & $2 \cdot 1 \%$ & $1 \cdot 3$ & 0.6 & $0 \cdot 1$ \\
\hline First time donors & 5076 & $11 \cdot 0 \%$ & $5 \cdot 6$ & $2 \cdot 8$ & 0.6 \\
\hline
\end{tabular}

$11 \cdot 0 \%$ in first time donors (table I). Supplemental testing was performed on $476(69 \cdot 9 \%)$ of the 681 specimens giving positive results on ELISA. All were reactive, $73 \cdot 1 \%$ to HIV $1,14 \cdot 7 \%$ to HIV 2 , and $12 \cdot 2 \%$ to both.

\section{OBSERVED SEROCONVERSIONS IN REPEAT DONORS}

Twenty nine repeat donors were identified who donated a seronegative unit of blood between January and May 1991 inclusive but on a later donation were found to be positive (all were confirmed by supplemental testing) (table II). Of these 29 seroconversions, 27 were for HIV 1, one was for HIV 2, and one was for both viruses. The time range between the seronegative and subsequent seropositive donations was from two to five months. The estimated dates of infection (eight weeks before the estimated date of seroconversion; fig 1) for all 29 seroconverters fell within the first five months of the year.

For 26 of the seroconverters the presumed date of seroconversion was within eight weeks of the donation of the seronegative unit of blood. The minimum rate of potentially HIV infected units collected from repeat donors during the first five months of 1991 was therefore $26 / 5831(4 \cdot 5 / 1000)$.

\section{INCIDENCE OF HIV INFECTION}

If each unit of blood represented an individual repeat donor the incidence of HIV infection derived from observed seroconversions would be (29/5831) over the five months, or $1 \cdot 2 \%$ per year.

The estimated total number of repeat donors (assuming donations every three months) is: $(5831 \times 12 / 5 \times 1 / 4)=3498 \cdot 6$.

Over the four periods (fig 2) encompassed by the study 29 incident infections were recognised. The number of incident infections over the nine periods throughout the year would be:

$(29 \times 9 / 4)=65 \cdot 25$.

Since the testing intervals only cover nine months, the annual number of incident infections would be:

$$
(65 \cdot 25 \times 12 / 9)=87 \text {. }
$$

The annual incidence of HIV infection in repeat donors would be:

$$
(87 / 3498 \cdot 6 \times 100)=2 \cdot 5 \% \text {. }
$$

POTENTIALLY INFECTIOUS UNITS IN REPEAT DONORS AND FIRST TIME DONORS

For repeat blood donors who donate four times a year the risk of a donor with incident HIV infection donating during the HIV antibody negative window period ranges from:

$$
(1 \cdot 2 / 100 \times 56 / 365 \times 4)=7 \cdot 4 / 1000 \text { to }
$$$$
(2 \cdot 5 / 100 \times 56 / 365 \times 4)=15 \cdot 3 / 1000 \text {. }
$$

For first time donors the same assumptions apply, but the donation is a once only event. The risk of a seroconverting donor giving blood while infectious would range from:

$$
\begin{gathered}
(1 \cdot 2 / 100 \times 56 / 365)=1 \cdot 8 / 1000 \text { to } \\
(2 \cdot 5 / 100 \times 56 / 365)=3 \cdot 8 / 1000 .
\end{gathered}
$$

\section{FALSE NEGATIVE HIV ANTIBODY TEST RESULTS}

Table III shows the number of HIV antibody positive units that would be incorrectly labelled negative according to different levels of laboratory sensitivity. At a sensitivity of $99 \%, 1 \cdot 3$ of the units collected from repeat donors would have been infected, and 5.6 units from first time donors. The respective rates would be $0 \cdot 2 / 1000$ units from repeat donors and $1 \cdot 1 / 1000$ units from first time donors.

ESTIMATED OVERALL RISK OF HIV INFECTED BLOOD DESPITE SCREENING

Table IV shows the relative importance of the different sources of contaminated blood from repeat 
TABLE IV-Estimated overall risk of blood donations with HIV infected blood in Abidjan despite HIV antibody screening

\begin{tabular}{|c|c|c|c|}
\hline & $\begin{array}{l}\text { Repeat donors } \\
\quad \text { (No of } \\
\text { units }=5831)\end{array}$ & $\begin{array}{c}\text { First time donors } \\
\text { (No of } \\
\text { units }=5076)\end{array}$ & $\begin{array}{c}\text { Total } \\
\text { (No of } \\
\text { units }=10907)\end{array}$ \\
\hline $\begin{array}{l}\text { Incident infections (units in window period } \\
\text { January-May } 1991^{\star} \text { ) }\end{array}$ & $43 \cdot 1-89 \cdot 2$ & $9 \cdot 1-19 \cdot 3$ & $52 \cdot 2-108 \cdot 5$ \\
\hline $\begin{array}{l}\text { False negative units, January-May } 1991 \\
\text { (assumes } 99 \% \text { test sensitivity) }\end{array}$ & 1.3 & $5 \cdot 6$ & 6.9 \\
\hline $\begin{array}{l}\text { Total units infected but negative for HIV } \\
\text { antibody } \\
\text { Rate/1000 units }\end{array}$ & $\begin{array}{r}44 \cdot 4-90 \cdot 5 \\
7 \cdot 6-15 \cdot 5\end{array}$ & $\begin{array}{c}14 \cdot 7-24 \cdot 9 \\
2 \cdot 9-4 \cdot 9\end{array}$ & $\begin{array}{c}59 \cdot 1-115 \cdot 4 \\
5 \cdot 4-10 \cdot 6\end{array}$ \\
\hline
\end{tabular}

$\star$ Based on calculated rate of $7 \cdot 4-15 \cdot 3 / 1000$ for repeat donors and $1 \cdot 8 \cdot 3 \cdot 8 / 1000$ for first time donors (see results)

and first time donors. Of a total of 10907 units collected from all donors from January to May inclusive, $59 \cdot 1$ to $115 \cdot 4$ units would have been potentially infected with HIV, for an overall rate of 5·4-10.6/1000 units. Only 6.9 infected units, $6-12 \%$ of the total infected units, would result from false negative results, assuming a sensitivity of $99 \%$ for laboratory testing. Among the potentially infectious units due to incident infections, $82-83 \%$ would be from repeat donors.

\section{Discussion}

Transfusion of HIV infected blood is probably the most efficient mode of transmission of HIV, most recipients of such contaminated blood themselves becoming infected. ${ }^{1}$ Despite intensive efforts and investment to guarantee the safety of the blood supply about one in every 94-185 screened units of blood in Abidjan remains potentially infectious for HIV. For blood collected from repeat donors the rate of infected blood despite screening may be as high as one in every 65-132 units. Although these rates are estimates, the directly observed incidence of seroconversion suggests a minimum rate of $4 \cdot 5 / 1000$ seronegative, HIV infected units from repeat donors. Receipt of a screened unit of blood in a city such as Abidjan may thus carry a two to three times greater risk of HIV infection than a needlestick exposure from an HIV infected patient. ${ }^{12}$

For both repeat and first time donors in Abidjan, the major source of infectious, HIV antibody negative blood is donation after infection but before seroconversion. As modern tests for HIV antibody have a high sensitivity laboratory error is probably the most frequent cause of false negative antibody test results. We used an arbitrary sensitivity rate of $99 \%{ }^{2}$ to compare the importance of false negative antibody test results with that of incident infections as a cause of contaminated blood units. Even in a population with a high prevalence of HIV antibody, such as first time donors in Abidjan, the rate of false negative results would have to be considerable to exceed the rate of infectious units due to seroconversions.

Our estimates of the incidence of HIV infection $(1 \cdot 2$ $2.5 \%$ per year) are close to measured incidence rates reported from cohort studies in other African cities with similar levels of HIV seroprevalence. ${ }^{13}$ The high rate of seroconversion for HIV 1, 27 times higher than that for HIV 2, corresponds with recent reports of an increase in the prevalence of HIV 1 but a stable prevalence of infection with HIV 2 in Abidjan (R Doorly et al, seventh international conference on AIDS, Florence, 1991; abstract MC42).

With currently available technology there is no simple way of reducing further this risk of HIV infection from screened blood. Donor deferral is difficult because risk factors for HIV infection are less obvious when the population prevalence is high and heterosexual transmission is the dominant mode of transmission (N Nzilambi et al, third intrnational conference on AIDS, Washington, DC, 1987; abstract W4.6). Further improvement in laboratory standards, assuming that $99 \%$ sensitivity for detection of HIV antibody is realistic, brings relatively little gain. Testing for HIV p24 antigen merits evaluation for detecting seroconversions,${ }^{14}$ but available evidence suggests that HIV p24 antigenaemia is less common in African people with HIV infection than in North Americans. ${ }^{15}$ This phenomenon may result from immune complex formation and may therefore not apply to units of blood in which HIV antibody is lacking. Testing of donated blood for HIV p24 antigen has been proposed in Bangkok ${ }^{16}$ but has not been evaluated in Africa.

This work suggests that in Abidjan, some 142 to 276 units of blood potentially infected with HIV are transfused annually. Though this should cause great concern, it is worth emphasising the great number of infections prevented since blood screening was introduced into this high prevalence donor population. In addition, HIV infections associated with transfusion are greatly outnumbered by infections resulting from other transmission routes. Our estimate of HIV infection incidence $(1 \cdot 2-2 \cdot 5 \%$ per year) in blood donors may not apply to all adults in Abidjan, but there clearly must be many thousands of new cases of HIV infection annually due to heterosexual transmission among the city's adult population of about one million.

To reduce further the transmission of HIV infection by blood transfusions in cities such as Abidjan recruitment of donors with especially low incidence and prevalence rates of HIV infection will need to be investigated. The age specific and sex specific distribution of HIV infection in the community can provide guidance about the best groups to target. For example, older people may have a low incidence of HIV infection and may be suitable as repeat donors ( $\mathrm{R}$ Schutz et al, sixth international conference on AIDS in Africa, Dakar, 1991; abstract MA 255); male adolescents tend to have a lower prevalence (and, presumably, incidence) than female adolescents. Selected groups such as religious communities merit examination to see whether they have low prevalence and incidence of HIV infection.

There is a need for studies in areas of high prevalence of HIV to measure directly the risks associated with blood transfusion that we have attempted to estimate. Tests for HIV p24 antigen should be evaluated, and for selected situations autotransfusions and use of blood substitutes may be feasible. Such interventions, however, will not be widely applicable in the developing world. The two most important conclusions from this study are that more attention is needed in Africa in choosing blood donors with a low incidence of HIV infection, and that absolute emphasis must be placed on avoiding transfusion in all but those whose need is most dire. This may require creation of national blood transfusion advisory committees to establish guidelines for the rational use of blood and mechanisms for their implementation. ${ }^{17}$

We thank Drs John Ward, Harrison Stetler, Helene Gayle, and James Curran for discussion, and we acknowledge the valuable comments and suggestions of the anonymous statistical referee.

1 Miller HG, Turner CF, Moses LE, eds. AIDS and the blood supply In: AIDS: the second decade. Washington, DC: National Academy Press, 1990:289-358.

2 Ward JW, Holmberg SD, Allen JR, Cohn DL, Critchley SE, Kleinman SH et al Transmission of human immunodeficiency virus (HIV) by blood transfusion screened as negative for HIV antibody. $N$ Engl f $\mathrm{Med}$ 1988;318:473-8.

3 Cumming PD, Wallace EL, Schorr JB, Dodd RY. Exposure of patients to human immunodeficiency virus through the transfusion of blood components that test antibody-negative. N Engl F Med 1989;321:941-6.

4 Busch MP, Eble BE, Khayam-Bashi H, Heilbron D, Murphy EL, Kwok S, et al. Evaluation of screened blood donations for human immunodeficiency et al. Evaluation of screened blood donations for human immunodeficiency
virus type 1 infection by culture and DNA amplification of pooled cells. virus type 1 infection by culur
NEngl F Med 1991;325:1-5.

5 Courouce A-M, Baudelot J, Elghouzzi MH, Gueguen M. Janot C, Lemaire $\mathrm{JM}$, et al. Prévalence et caractéristiques épidémiologiques des sujets 
découverts infectés par le VIH à l'occasion d'un don de sang Rev Fr Transfus Hemobiol 1990;33:431-8.

6 Zuck TF. Transfusion-transmitted AIDS reassessed. $N$ Engl f Med 1988;318: 511-2.

7 Julien A-M, Courouce A-M, Richard D, Favre M, Lefrere J-J, Habibi B. Transmission of HIV by blood from seronegative donors. Lancet 1988;ii: $1248-9$

8 Piot P, Plummer FA, Mhalu FS, Lamboray J-L, Chin J, Mann JM. AInS: an international perspective. Science 1988;239:573-9.

9 De Cock KM, Porter A, Kouadio J, Maran M, Gnaore E, Adjorlolo G, et al. Rapid and specific diagnosis of HIV-1 and HIV-2 infections: an evaluation Rapid and specific diagnosis of HIV-1 an
of testing strategies. AIDS 1990;4:875-8.

10 Rutherford GW, Lifson AR, Hessol NA, Darrow WW, O'Malley PM, Buchbinder $\mathrm{P}$, et al. Course of HIV-1 infection in a cohort of homosexual Buchbinder $P$, et al. Course of HIV-1 infection in a cohort of homo

11 De Cock KM, Niland JC, Lu H-P, Rahimian A, Edwards V, Shriver K, et al. De Cock KM, Niland JC, Lu H-P, Rahimian A, Edwards $\mathrm{V}$, Shriver $\mathrm{K}$, et al.
Experience with human immunodeficiency virus infection in patients with hepatitis B virus and hepatitis delta virus infection in Los Angeles, 1977-1985. Am f Epidemiol 1988;127:1250-60.

12 Marcus R and the CDC Cooperative Needlestick Surveillance Group. Surveil- lance of health care workers exposed to blood from patients infected with the human immunodeficiency virus. $N$ Engl f Med 1988;319:1118-23.

13 N'Galy B, Ryder RW, Bila K, Mwandagalirwa K, Colebunders RL, Francis $\mathrm{H}$, et al. Human immunodeficiency virus infection among employees in an African hospital. N Engl F Med 1988;319:1123-7.

14 Alter HJ, Epstein JS, Swenson SG, VanRaden MJ, Ward JW, Kaslow RA, et al. Prevalence of human immunodeficiency virus type 1 p 24 antigen in US blood donors - an assessment of the efficacy of testing in donor screening. N Engl F Med 1990;323:1312-7.

15 Brown $C$, Kline $R$, Atibu L, Francis $H$, Ryder $R$, Quinn TC Prevalence of HIV-1 p24 antigenemia in African and North American populations and correlation with clinical status. AIDS 1991;5:89-92.

16 Chiewsilp P, Isarangkura P, Poonkasem A, Iamsilp W, Khamenkhetkran M, Stabunswadigan $S$. Risk of transmission of HIV by seronegative blood. Lancet 1991;338:1341.

17 Reducing the risk of transmission of HIV by blood transfusion. Bull WHO $1990 ; 68: 262-4$

\title{
Randomised controlled trial of short term treatment to eradicate Helicobacter pylori in patients with duodenal ulcer
}

\author{
Shorland W Hosking, Thomas K W Ling, Man Yee Yung, Augustine Cheng, \\ Sydney C S Chung, Joseph W C Leung, Arthur K C Li
}

\begin{abstract}
Objective-To determine whether one week's drug treatment is sufficient to eradicate Helicobacter pylori in patients with duodenal ulcer.

Design - Single blind, randomised controlled trial. Setting-Specialised ulcer clinic in a teaching hospital.

Patients -155 patients with $H$ pylori and a duodenal ulcer verified endoscopically which had either bled within the previous 24 hours or was causing dyspepsia.

Interventions-Patients were allocated randomly to receive either omeprazole for four weeks plus bismuth $120 \mathrm{mg}$, tetracycline $500 \mathrm{mg}$, and metronidazole $400 \mathrm{mg}$ (all four times a day) for the first week $(n=78)$, or omeprazole alone for four weeks $(n=77)$. Further endoscopy was performed four weeks after cessation of all drugs.
\end{abstract}

Main outcome measures-Presence or absence of $H$ pylori (by urease testing, microscopy, and culture of antral biopsy specimens), duodenal ulcer, and side effects.

Results-Eradication of $\boldsymbol{H}$ pylori occurred in $\mathbf{7 0}$ (95\%) patients taking the four drugs $(95 \%$ confidence interval $86 \%$ to $97 \%$ ) compared with three $(4 \%)$ patients taking omeprazole alone (1\% to $11 \%)$. Duodenal ulcers were found in four $(5 \%)$ patients taking the four drugs (2\% to $12 \%)$ and in $16(22 \%)$ patients taking omeprazole alone (14\% to $32 \%)$. Mild dizziness was the only reported side effect (six patients in each group) and did not affect compliance.

Conclusions-A one week regimen of bismuth, tetracycline, and metronidazole is safe and effective in eradicating $\boldsymbol{H}$ pylori and reduces the number of duodenal ulcers four weeks after completing treatment.

\section{Introduction}

The linking of relapse of duodenal ulcers with Helicobacter pylori has been a considerable advance in managing patients with ulcer disease. Several studies have shown that in patients with duodenal ulcer and $H$ pylori eradication of $H$ pylori during ulcer healing is followed by duodenal ulcer relapse in only $5-10 \%$ of patients after one year compared with around $85 \%$ relapse in patients without eradication. ${ }^{1-3}$ The most effective regimens against $H$ pylori usually consist of three drugs taken three to four times a day for between two and six weeks. ${ }^{1-4}$ Patient compliance with such treatment regimens can be difficult. Furthermore, side effects increase with duration of treatment. For these reasons we performed a randomised controlled trial to investigate whether one week of treatment is sufficient to eradicate $H$ pylori.

\section{Patients and methods}

We performed antral biopsies on all patients undergoing oesophagogastroduodenoscopy during a four month period at this hospital and found to have an active duodenal ulcer. We included patients with dyspeptic symptoms and also those with gastrointestinal bleeding from their duodenal ulcer. (Those with gastrointestinal bleeding had endoscopy within 24 hours of admission.) The biopsy specimens were tested for the presence of urease using a commercial kit (CLO test, Delta West, Western Australia). All patients with urease positive test results were considered for entry to the trial. Exclusion criteria were haemodynamic instability, previous surgery for acid reduction, and pregnancy. Once entered, patients were randomised by instructions in consecutively numbered sealed opaque envelopes to receive either omeprazole for four weeks, plus colloidal bismuth subcitrate $120 \mathrm{mg}$ four times daily, tetracycline $500 \mathrm{mg}$ four times daily, and metronidazole $400 \mathrm{mg}$ four times daily for the first week, or omeprazole alone for four weeks. Drug treatment was started within 24 hours of endoscopy.

Eight weeks later (four weeks after all treatment had finished) the patients reattended the hospital. At this visit they were asked about any side effects they had experienced, followed by further endoscopy to look for ulcer healing. At the same time antral biopsies for microscopy, culture, and detection of urease were performed. The staff performing the endoscopic and bacteriological assessments were unaware of the drugs the patient had been taking.

Bacteriological techniques - Two antral biopsy specimens were minced aseptically and Gram stained to detect Gram negative spiral organisms. The minced tissue was cultured on Columbia agar (Oxoid) supplemented with $5 \%$ horse blood and incubated for five days under microaerophilic conditions. The identity of $H$ pylori was confirmed by colony morphology, Gram stain, and positive biochemical test results (oxidase, catalase, and urease). Eradication of $H$ 